\title{
Fluorinated ortho-linked polyamides derived from non-coplanar 1,1'-thiobis(2-naphthol): synthesis and characterization
}

\begin{abstract}
Abbas Shockravi ${ }^{1}$, Ali Javadi ${ }^{1}$ and Ebrahim Abouzari-Lotf ${ }^{2}$
A novel sulfide-bridged bis(ether amine) monomer containing bulky trifluoromethyl and naphthyl substituents, 1,1'-thiobis[2-(4amino-2-trifluoromethylphenoxy)naphthalene], was synthesized from the halogen displacement of 2-chloro-5-nitrobenzotrifluoride with 1,1'-thiobis(2-naphthol) in the presence of potassium carbonate, followed by the palladium on activated carbon-catalyzed reduction of bis(ether nitro) intermediate, 1,1'-thiobis[2-(4-nitro-2-trifluoromethylphenoxy)naphthalene], with hydrazine hydrate in refluxing ethanol. New series of fluorinated poly(ether amide)s (PEA-1-8) were synthesized from bis(ether amine) with various commercially available aromatic diacids (1-8) via a direct polycondensation method with triphenyl phosphite and pyridine. The resulting polymers had inherent viscosities, ranging from 0.61 to $0.93 \mathrm{dl} \mathrm{g}^{-1}$. All the polymers showed outstanding solubility and could be easily dissolved in amide-type polar aprotic solvents (for example, $\mathbf{N}$-methyl-2-pyrrolidone, dimethyl sulfoxide and $\mathrm{N}, \mathrm{N}$-dimethylacetamide (DMAc)), and even dissolved in less polar solvents (for example, pyridine, tetrahydrofuran and chloroform). In addition, these polymers could be cast into transparent, flexible and tough films from DMAc solutions. The glasstransition temperatures were recorded between 209 and $251^{\circ} \mathrm{C}$, and $10 \%$ weight loss temperatures were in excess of $470{ }^{\circ} \mathrm{C}$ in nitrogen and $450{ }^{\circ} \mathrm{C}$ in air atmosphere. Moreover, these PEAs exhibited low refractive indices $(n=1.5614-1.5813)$, birefringence $(\Delta=0.0055-0.0097)$ and dielectric constants $(\varepsilon=2.68-2.75)$.
\end{abstract}

Polymer Journal (2011) 43, 816-825; doi:10.1038/pj.2011.74; published online 24 August 2011

Keywords: fluorinated poly(ether amide)s; improved solubility; low refractive index; ortho-linked; sulfur-containing polymers; thermal stability

\section{INTRODUCTION}

Aromatic polyamides (aramids) are well known for their high thermal stability, outstanding mechanical strength and good chemical resistance that qualify them as high-performance materials. ${ }^{1-4}$ However, most aramids are generally difficult to process because of their limited solubility in common organic solvents and high melting or glasstransition temperatures caused by the highly rigid and regular polymer backbones and the strong intermolecular interactions through hydrogen bonding. Furthermore, the high moisture absorptions of aramids, compared with other polymer materials, have resulted in obvious negative effects on their mechanical properties, as well as electrical insulating and dielectric performance. ${ }^{5}$ Therefore, various attempts have been made to enhance their solubilities and processabilities either by introducing flexible linkages, ${ }^{6}$ bulky pendant groups $^{7}$ or fluorinated substituents ${ }^{8}$ into the polymer backbones.

Fluorinated polymers have often been used in many high-technology fields, such as surfaces and coatings, ${ }^{9}$ photonic and electronic applications, ${ }^{10-12}$ and gas-separation membranes. ${ }^{13,14}$ Recently, some efforts have been made on preparing fluorinated aramids, especially the trifluoromethyl $\left(\mathrm{CF}_{3}\right)$-containing poly(ether amide)s (PEAs). ${ }^{15-18}$
It has been proved that the incorporation of bulky $-\mathrm{CF}_{3}$ moieties into polyamide backbones resulted in great benefits for improving polymer solubility and optical transparency, as well as electrical and dielectric performance, which was attributed to the low polarizability of the C-F bond and the increase in free volume. ${ }^{19,20}$

Recent studies demonstrated that the introduction of both flexible ether linkages and bulky naphthalene units into the polymer chains can enhance the solubility and processability of aramids, without any significant reduction in thermal stability. ${ }^{21-23}$ In addition, the introduction of flexible thioether linkages into the polymer chain could be another important way to induce important variations of properties, such as lower melting or glass-transition temperatures, better fire-retardant properties, less water absorption and higher refractive indices. $^{24-27}$

Another attractive approach employed to increase the solubility of polyamides without much deteriorating their inherent excellent properties is the incorporation of less symmetric units such as ortho-catenated aromatic rings in the main chains, which leads to a reduction in crystallinity. ${ }^{28-31}$ For example, Hsiao et al. ${ }^{31}$ investigated the influence of introducing ortho-phenylene units into the polymer

${ }^{1}$ Faculty of Chemistry, Tarbiat Moallem University, Tehran, Iran and ${ }^{2}$ Young Researchers Club, Islamic Azad University, North Tehran Branch, Tehran, Iran Correspondence: Professor A Shockravi, Faculty of Chemistry, Tarbiat Moallem University, Mofatteh Avenue, No. 49, Tehran 15719-14911, Iran. E-mail: abbas_shockravi@yahoo.co.uk

Received 8 April 2011; revised 20 June 2011; accepted 22 June 2011; published online 24 August 2011 
chains and observed that ortho-linked polyamides are far more processable than their meta- or para-linked analogs. In the previous studies, we prepared the polyamides derived from ortho-linked aromatic diacids, such as $2,2^{\prime}$-sulfide-bis(4-methyl phenoxy acetic acid) or $1,1^{\prime}$-sulfide-bis(2-naphthoxy acetic acid), with commercial diamines. ${ }^{32,33}$ It was found that the formation of non-coplanar conformation due to the presence of ortho-sulfide or sulfoxide linkages between two aromatic rings could disturb interchain packing, reduce glass-transition temperature and increase solubility.

In a continuation of these studies and our recent efforts to develop high-performance fluorinated polymers with excellent solubility and high thermal stability, as well as low refractive index and low dielectric constant, ${ }^{34-37}$ the current work reports the synthesis and characterization of a series of fluorinated PEAs from a $\mathrm{CF}_{3}$-containing diamine, $1,1^{\prime}$-thiobis[2-(4-amino-2-trifluoromethylphenoxy)naphthalene] (DA), with various commercially available aromatic dicarboxylic acids. In addition to the bulky $-\mathrm{CF}_{3}$ and naphthyl groups, the incorporation of flexible ether and thioether linkages, and also the formation of bent structures due to the presence of ortho-links, would decrease polymer interchain interactions and generally disturb the coplanarity of aromatic units to reduce packing efficiency and crystallinity. Thus, the polymers would be expected to exhibit good solubility in organic solvents and low dielectric constants. The synthesis and properties of these fluorinated aramids such as thermal and solubility properties, as well as moisture absorption, refractive index, birefringence and dielectric constant, are investigated, and the effects of the chemical structures of polymers on the physical properties are also discussed.

\section{EXPERIMENTAL PROCEDURE}

\section{Materials}

1,1'-Thiobis(2-naphthol) (TBN) was prepared according to the reported procedure ${ }^{38}$ and recrystallized from ethanol. Potassium carbonate $\left(\mathrm{K}_{2} \mathrm{CO}_{3}\right)$ (Fluka, Buchs, Switzerland), 2-chloro-5-nitrobenzotrifluoride (Acros, Phillipsburg, NJ, USA), 10\% palladium on activated carbon (Pd/C; Fluka) and hydrazine monohydrate (Acros, Geel, Belgium) were used as received. Reagent-grade aromatic dicarboxylic acids, such as terephthalic acid (1; Merck, Darmstadt, Germany), isophthalic acid (2; Merck), pyridine 2,5-dicarboxylic acid (3; Merck), pyridine 2,6-dicarboxylic acid (4; Merck), 4,4'-biphenyldicarboxylic acid (5; Aldrich, Taufkirchen, Germany), 4,4'-oxydibenzoic acid (6; Aldrich), 4,4'-(hexafluoroisopropylidene)dibenzoic acid (7; Aldrich, St Louis, MO, USA) and 4,4'-sulfonyldibenzoic acid (8; Aldrich), were used as received. $N$-methyl-2-pyrrolidone (NMP, Merck) and pyridine (Fluka) were purified by distillation under reduced pressure over calcium hydride before use and stored over $4 \AA$ molecular sieves. Triphenyl phosphite (Merck) was used without previous purification. $\mathrm{LiCl}$ (Merck) was dried under vacuum at $180^{\circ} \mathrm{C}$ before use.

\section{Measurements}

Fourier transform infrared (FTIR) spectra were recorded in potassium bromide $(\mathrm{KBr})$ pellets on a Perkin Elmer FT spectrum RX1 (Perkin Elmer, Norwalk, CT, USA) over the range $400-4000 \mathrm{~cm}^{-1} .{ }^{1} \mathrm{H}$ NMR $(500 \mathrm{MHz}),{ }^{13} \mathrm{C}$ NMR $(125 \mathrm{MHz})$ and ${ }^{19} \mathrm{~F}$ NMR $(470 \mathrm{MHz})$ spectra were measured on a Bruker AVANCE-500 (Bruker BioSpin, Rheinstetten, Germany) at an operating temperature of $25^{\circ} \mathrm{C}$. Elemental analysis was performed by a Perkin Elmer 2004 (II) $\mathrm{CHN}$ analyzer. Inherent viscosities $\left(\eta_{\mathrm{inh}}=\ln \eta_{\mathrm{r}} / \mathrm{c}\right.$ at a concentration of $0.5 \mathrm{~g} \mathrm{dl}^{-1}$ ) were measured with an Ubbelohde suspended-level viscometer (Canon Instrument Co., State College, PA, USA) at $30^{\circ} \mathrm{C}$ using N,N-dimethylacetamide (DMAc) as solvent. Melting points (uncorrected) were measured with an Electrothermal Engineering LTD 9200 apparatus (Essex, UK). Wideangle X-ray diffraction measurements were performed at room temperature on a PW 1800 diffractometer (Philips, Eindhoven, Netherlands) with graphitemonochromatized $\mathrm{Cu} K \alpha$ radiation $(\lambda=1.5401 \AA)$. The scanning rate was $0.08^{\circ} \mathrm{s}^{-1}$ over a range of $2 \theta=4-80^{\circ}$. Thermogravimetric analyses were conducted with a thermal analyzer (Du Pont 2000, Wilmington, DE, USA) under nitrogen and air atmospheres at a heating rate of $10^{\circ} \mathrm{C} \mathrm{min}^{-1}$ from 50 to $900^{\circ} \mathrm{C}$. Glass-transition temperatures, taken as the mid-point of the change in slope of baseline, were measured on a 2010 Differential Scanning Calorimetry (DSC) (TA Instruments, Brussels, Belgium), with a heating rate of $10^{\circ} \mathrm{C} \mathrm{min}^{-1}$. The refractive indices of the synthesized polymers were measured with a prism coupler (Metricon 2000, Pennington, NJ, USA) at room temperature in open air. The measurements were made at a wavelength of $1320 \mathrm{~nm}$. Using linearly polarized laser light with parallel (transverse electric, TE) and perpendicular (transverse magnetic, TM) polarization to the film plane, the in-plane $\left(n_{\mathrm{TE}}=n_{x y}\right)$ and out-of-plane $\left(n_{\mathrm{TM}}=n_{z}\right)$ refractive indices of the samples were determined. The in-plane/out-of-plane birefringence $(\Delta n)$ was calculated as a difference between $n_{\mathrm{TE}}$ and $n_{\mathrm{TM}}$. The average refractive index was calculated according to equation: $n_{\mathrm{AV}}=\left(2 n_{\mathrm{TE}}+n_{\mathrm{TM}}\right) / 3$. The dielectric constant $(\varepsilon)$ was estimated from the measured refractive indices based on the Maxwell equation $\left(\varepsilon=1.10 n_{\mathrm{AV}}{ }^{2}\right) .{ }^{39}$

\section{Monomer synthesis}

Synthesis of 1,1'-thiobis[2-(4-nitro-2-trifluoromethylphenoxy)naphthalene] (DN). TBN $(10 \mathrm{mmol}, 3.18 \mathrm{~g})$ and 2-chloro-5-nitrobenzotrifluoride $(20 \mathrm{mmol}, 4.50 \mathrm{~g})$ were dissolved in $50 \mathrm{ml}$ of dimethyl sulfoxide (DMSO) in a 250 -ml roundbottomed flask. Further, $\mathrm{K}_{2} \mathrm{CO}_{3}(22 \mathrm{mmol}, 3.04 \mathrm{~g})$ was added, and the suspension mixture was heated at $110^{\circ} \mathrm{C}$ for $12 \mathrm{~h}$. The mixture was allowed to cool and then poured into $300 \mathrm{ml}$ of water to give a yellow solid, which was collected, washed with water repeatedly and dried in vacuum. The crude product was recrystallized from $\mathrm{N}, \mathrm{N}$-dimethylformamide/water to give palecream crystals $(5.77 \mathrm{~g}, 83 \%)$; melting point $=220-222^{\circ} \mathrm{C}$; IR $(\mathrm{KBr}): 1525,1349$ ( $-\mathrm{NO}_{2}$ stretch), 1288, 1249 (C-O stretch) and 1140 (C-F stretch); ${ }^{1} \mathrm{H}$ NMR<smiles>CC(C)(C)O[N+](=O)[O-]</smiles>

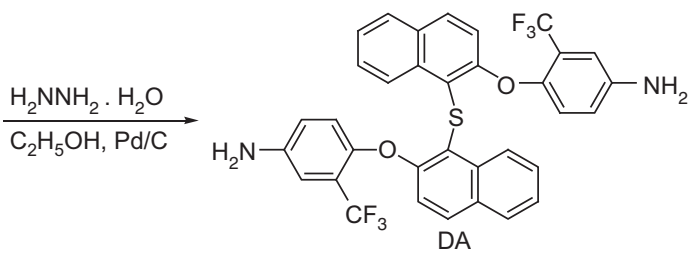

Scheme 1 Synthesis of the diamine monomer 1,1'-thiobis[2-(4-amino-2-trifluoromethylphenoxy)naphthalene. 
$\left(500 \mathrm{MHz}, \mathrm{DMSO}-d_{6}\right) ; \delta 8.42\left(\mathrm{~d}, J=8.3 \mathrm{~Hz}, 2 \mathrm{H}, \mathrm{H}_{\mathrm{i}}\right), 8.27(\mathrm{~d}, J=2.3 \mathrm{~Hz}, 2 \mathrm{H}$, $\left.\mathrm{H}_{\mathrm{a}}\right), 8.21\left(\mathrm{dd}, J=9.1,2.3 \mathrm{~Hz}, 2 \mathrm{H}, \mathrm{H}_{\mathrm{b}}\right), 7.99\left(\mathrm{~d}, J=8.8 \mathrm{~Hz}, 2 \mathrm{H}, \mathrm{H}_{\mathrm{e}}\right), 7.94(\mathrm{~d}$, $\left.J=7.9 \mathrm{~Hz}, 2 \mathrm{H}, \mathrm{H}_{\mathrm{f}}\right), 7.53\left(\mathrm{t}, J=7.0 \mathrm{~Hz}, 2 \mathrm{H}, \mathrm{H}_{\mathrm{h}}\right), 7.49\left(\mathrm{t}, J=7.9 \mathrm{~Hz}, 2 \mathrm{H}, \mathrm{H}_{\mathrm{g}}\right), 7.20$ $\left(\mathrm{d}, J=8.8 \mathrm{~Hz}, 2 \mathrm{H}, \mathrm{H}_{\mathrm{d}}\right)$ and $6.70\left(\mathrm{~d}, J=9.1 \mathrm{~Hz}, 2 \mathrm{H}, \mathrm{H}_{\mathrm{c}}\right)$ p.p.m.; ${ }^{13} \mathrm{C} \mathrm{NMR}$ $\left(125 \mathrm{MHz}, \mathrm{DMSO}-d_{6}\right) ; \delta 159.9,152.5,142.4,134.7,132.7,132.6,130.3$, $129.5,128.5,127.2,125.7,123.7,123.2,125.9,123.7,121.6,119.4$ (q, $\left.{ }^{1} J_{\mathrm{C}-\mathrm{F}}=272 \mathrm{~Hz}\right), \quad 121.1, \quad 119.6,119.3,119.1,118.8 \quad\left(\mathrm{q},{ }^{2} J_{\mathrm{C}-\mathrm{F}}=32 \mathrm{~Hz}\right)$ and 118.2 p.p.m.; ${ }^{19} \mathrm{~F}$ NMR $\left(470 \mathrm{MHz}, \mathrm{DMSO}-d_{6}\right) ; \delta-61.77$ (s, $\left.-\mathrm{CF}_{3}\right)$ p.p.m.; and anal. calcd for $\mathrm{C}_{34} \mathrm{H}_{18} \mathrm{~F}_{6} \mathrm{~N}_{2} \mathrm{O}_{6} \mathrm{~S}$ : C, 58.62\%; H, 2.60\%; and N, 4.02\%. Observed C, $58.55 \%$; $\mathrm{H}, 2.63 \%$; and $\mathrm{N}, 4.07 \%$.

Synthesis of 1,1'-thiobis[2-(4-amino-2-trifluoromethylphenoxy)naphthalene] (DA). To a suspension solution of the purified dinitro compound DN $(10 \mathrm{mmol}$, $6.96 \mathrm{~g})$ and $10 \% \mathrm{Pd} / \mathrm{C}(0.10 \mathrm{~g})$ in ethanol $(50 \mathrm{ml})$, hydrazine monohydrate $\left(10 \mathrm{ml}\right.$ ) was added dropwise to the stirred mixture at $80^{\circ} \mathrm{C}$ within $1 \mathrm{~h}$. After complete addition, the mixture was heated at the reflux temperature for about $10 \mathrm{~h}$. The reaction solution was filtered hot to remove $\mathrm{Pd} / \mathrm{C}$, and the filtrate was then distilled to remove the solvent. The crude product was purified by recrystallization from methanol/water to give yellow-powdery crystals $(5.78 \mathrm{~g}$, 91\%); melting point $=130-132^{\circ} \mathrm{C}$; $\mathrm{IR}(\mathrm{KBr}): 3464,3383$ (N-H stretch), 1228 (C-O stretch), 1127 (C-F stretch), 1047, 1000, 939, 907, 868, 814, 757, 667 and $532 \mathrm{~cm}^{-1} ;{ }^{1} \mathrm{H}$ NMR $\left(500 \mathrm{MHz}, \mathrm{CDCl}_{3}\right) ; \delta 8.81\left(\mathrm{~d}, J=8.5 \mathrm{~Hz}, 2 \mathrm{H}, \mathrm{H}_{\mathrm{i}}\right), 7.72(\mathrm{~d}$, $\left.J=7.9 \mathrm{~Hz}, 2 \mathrm{H}, \mathrm{H}_{\mathrm{f}}\right), 7.66\left(\mathrm{~d}, J=8.9 \mathrm{~Hz}, 2 \mathrm{H}, \mathrm{H}_{\mathrm{e}}\right), 7.48\left(\mathrm{t}, J=7.0 \mathrm{~Hz}, 2 \mathrm{H}, \mathrm{H}_{\mathrm{h}}\right), 7.38$ $\left(\mathrm{t}, J=7.9 \mathrm{~Hz}, 2 \mathrm{H}, \mathrm{H}_{\mathrm{g}}\right), 6.88\left(\mathrm{~d}, J=8.9 \mathrm{~Hz}, 2 \mathrm{H}, \mathrm{H}_{\mathrm{d}}\right), 6.87\left(\mathrm{~d}, J=2.4 \mathrm{~Hz}, 2 \mathrm{H}, \mathrm{H}_{\mathrm{a}}\right)$, $6.58\left(\mathrm{dd}, J=8.7,2.4 \mathrm{~Hz}, 2 \mathrm{H}, \mathrm{H}_{\mathrm{b}}\right), 6.29\left(\mathrm{~d}, J=8.7 \mathrm{~Hz}, 2 \mathrm{H}, \mathrm{H}_{\mathrm{c}}\right)$ and $3.66(\mathrm{~s}, 4 \mathrm{H},-$ $\mathrm{NH}_{2}$ ) p.p.m.; ${ }^{13} \mathrm{C}$ NMR $\left(125 \mathrm{MHz}\right.$, DMSO- $\left.d_{6}\right) ; \delta 155.7,147.5,141.6,135.6$, $131.2,130.4,128.3,127.4,126.6,125.3,126.7,124.5,122.3,120.2(\mathrm{q}$, $\left.{ }^{1} J_{\mathrm{C}-\mathrm{F}}=272 \mathrm{~Hz}\right), 122.7,122.4,122.2,121.9\left(\mathrm{q},{ }^{2} J_{\mathrm{C}-\mathrm{F}}=31 \mathrm{~Hz}\right), 122.2,121.2$, 119.8, 119.0 and 113.4 p.p.m.; ${ }^{19} \mathrm{~F}$ NMR $\left(470 \mathrm{MHz}, \mathrm{CDCl}_{3}\right) ; \delta-62.19$ (s, $-\mathrm{CF}_{3}$ ) p.p.m.; anal. calcd for $\mathrm{C}_{34} \mathrm{H}_{22} \mathrm{~F}_{6} \mathrm{~N}_{2} \mathrm{O}_{2} \mathrm{~S}$ : C, $64.15 \%$; $\mathrm{H}, 3.48 \%$; and $\mathrm{N}$, $4.40 \%$. Observed C, $64.03 \%$; $\mathrm{H}, 3.51 \%$; and $\mathrm{N}, 4.35 \%$.

Synthesis of fluorinated PEAs. A typical synthetic procedure for polyamide PEA-1 is described as follows. A mixture of $0.636 \mathrm{~g}(1 \mathrm{mmol})$ of DA, $0.166 \mathrm{~g}$ ( $1 \mathrm{mmol}$ ) of terephthalic acid, $0.3 \mathrm{~g}$ of $\mathrm{LiCl}, 0.6 \mathrm{ml}$ of triphenyl phosphite, $0.6 \mathrm{ml}$ of pyridine and $3 \mathrm{ml}$ of NMP was heated and stirred at $120^{\circ} \mathrm{C}$ for $4 \mathrm{~h}$ under nitrogen atmosphere. As the polycondensation proceeded, the reaction mixture became viscous gradually. The viscosity of reaction solution increased after $1 \mathrm{~h}$, and additional amount of NMP $(1 \mathrm{ml})$ was added to the reaction mixture. At the end of the reaction, the polymer solution was poured slowly into $300 \mathrm{ml}$ of methanol under rapid stirring. The product was filtered, washed thoroughly with hot water $(2 \times 100 \mathrm{ml})$ and methanol $(100 \mathrm{ml})$, and dried under vacuum at $100^{\circ} \mathrm{C}$ overnight. Further purification was carried out by dissolving the polymer in DMAc, filtering the polymer solution and then precipitating it into methanol. The inherent viscosity of the polymer in DMAc was $0.91 \mathrm{dlg}^{-1}$, measured at a concentration of $0.5 \mathrm{~g} \mathrm{dl}^{-1}$ at $30^{\circ} \mathrm{C}$. IR (KBr): 3302, 3057, 1666, 1534, 1495, 1456, 1424, 1325, 1248, 1217, 1133, 1052, 1000 and $816 \mathrm{~cm}^{-1}$. Anal. calcd for $\mathrm{C}_{42} \mathrm{H}_{24} \mathrm{~F}_{6} \mathrm{~N}_{2} \mathrm{O}_{4} \mathrm{~S}$ : C, $65.79 \%$; $\mathrm{H}, 3.16 \%$; and N, 3.65\%. Observed C, $65.60 \%$; H, 3.24\%; and N, 3.53\%. All the other PEAs were also prepared using similar procedures.

\section{RESULTS AND DISCUSSION}

Monomer synthesis

The new $\mathrm{CF}_{3}$-containing bis(ether amine) (DA) was prepared in a two-step process as shown in Scheme 1. The first step is an aromatic nucleophilic chloro-displacement reaction of 2-chloro-5-nitrobenzotrifluoride with the potassium phenolate of TBN formed in situ by the treatment with $\mathrm{K}_{2} \mathrm{CO}_{3}$ in DMSO. The target bis(ether amine) (DA) was readily obtained in high yields by the Pd/C-catalyzed reduction of the intermediate dinitro compound (DN) with hydrazine hydrate in refluxing ethanol. The structures of the dinitro compound $\mathrm{DN}$ and the diamine monomer DA were confirmed by ${ }^{1} \mathrm{H}$ NMR, ${ }^{13} \mathrm{C}$ NMR, ${ }^{19} \mathrm{~F}$ NMR, FTIR and elemental analysis. Figures 1 and 2, respectively, illustrate the ${ }^{1} \mathrm{H}$ NMR and ${ }^{13} \mathrm{C}$ NMR spectra of the synthesized compounds. The ${ }^{1} \mathrm{H}$ NMR spectra (Figure 1) confirm that the nitro a<smiles>O=[N+]([O-])c1ccc(Oc2ccc3ccccc3c2Sc2c(Oc3ccc([N+](=O)[O-])cc3C(F)(F)F)ccc3c(F)cccc23)c(C(F)(F)F)c1</smiles>

DN

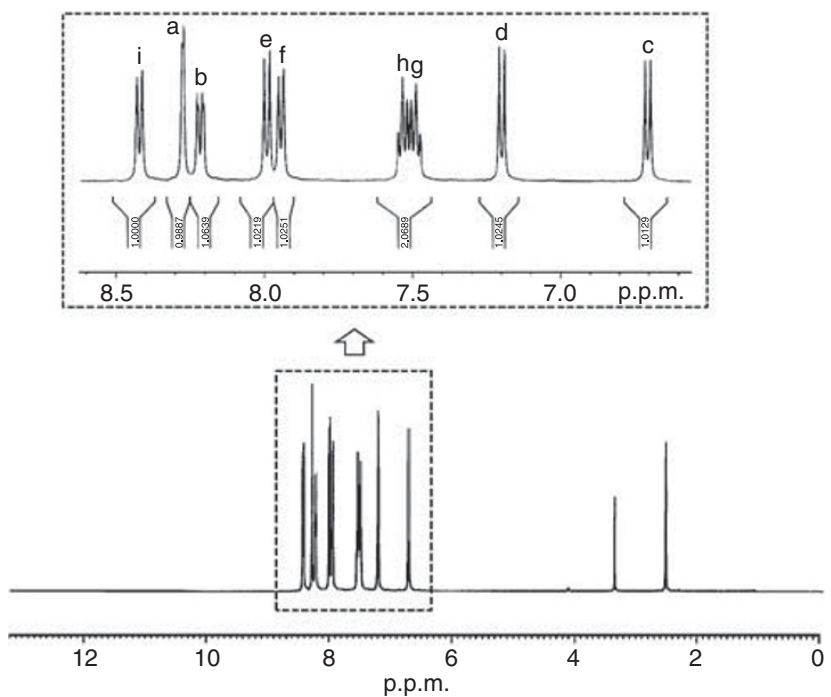

b
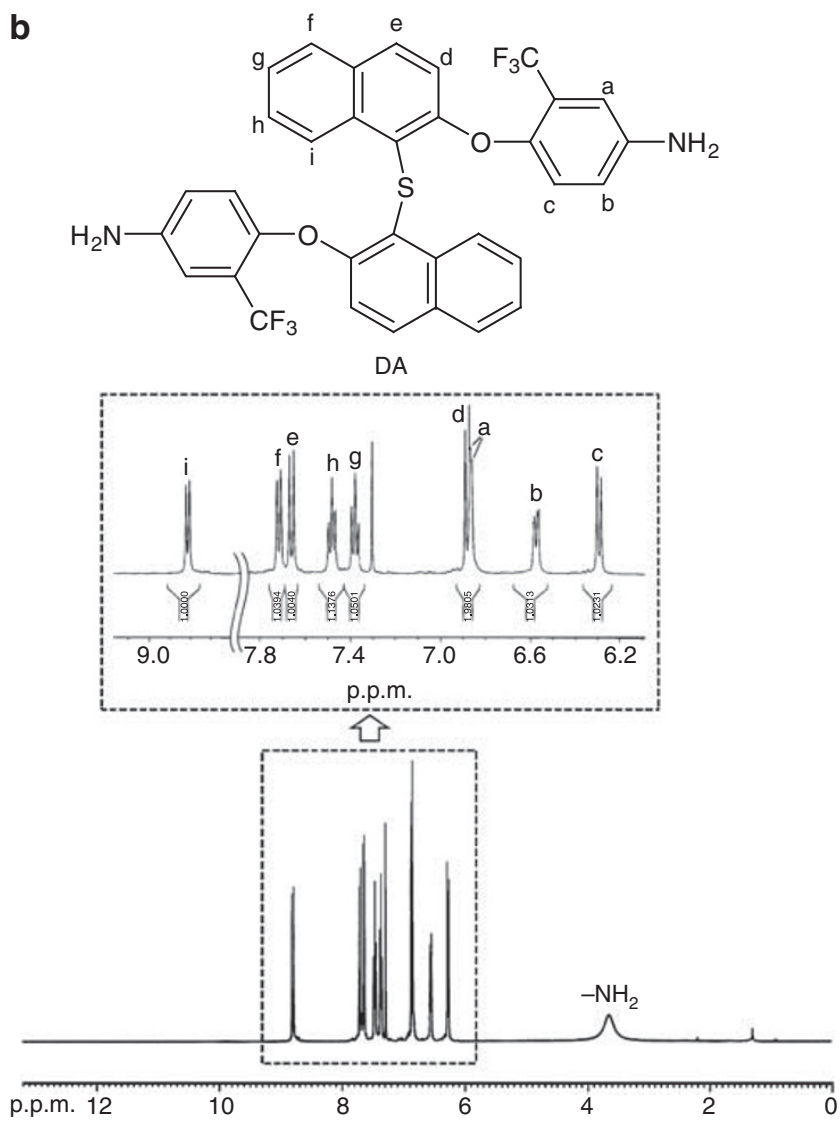

Figure $1^{1} \mathrm{H}$ NMR spectra of (a) dinitro compound 1,1'-thiobis[2-(4-nitro-2trifluoromethylphenoxy)naphthalene] and (b) diamine monomer 1,1'thiobis[2-(4-amino-2-trifluoromethylphenoxy)naphthalene. 
a<smiles></smiles>

DN

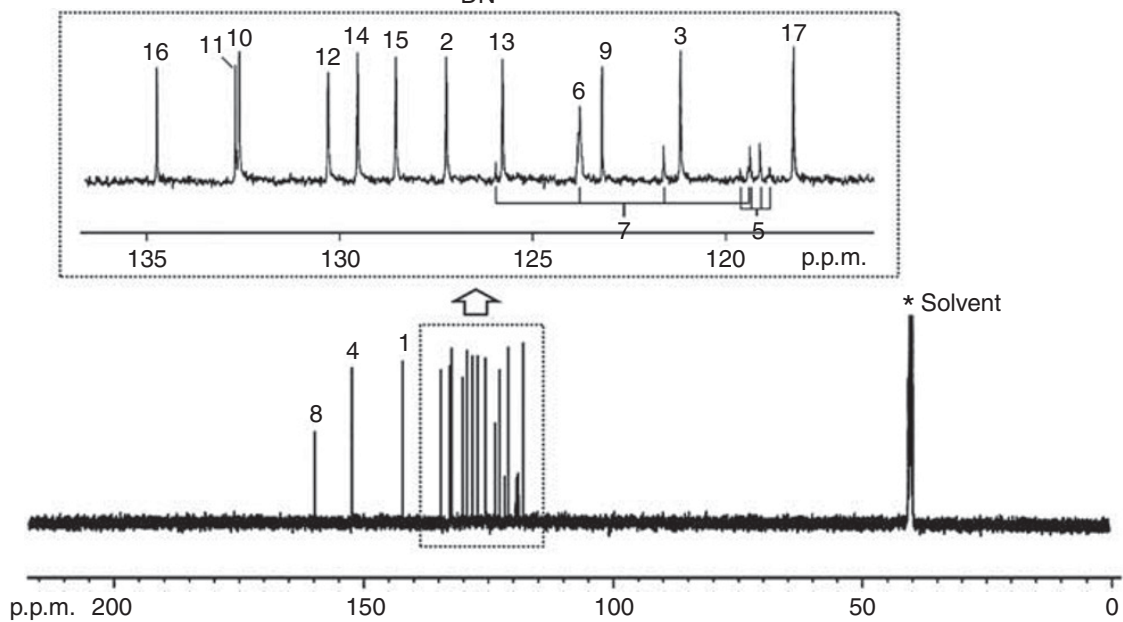

b
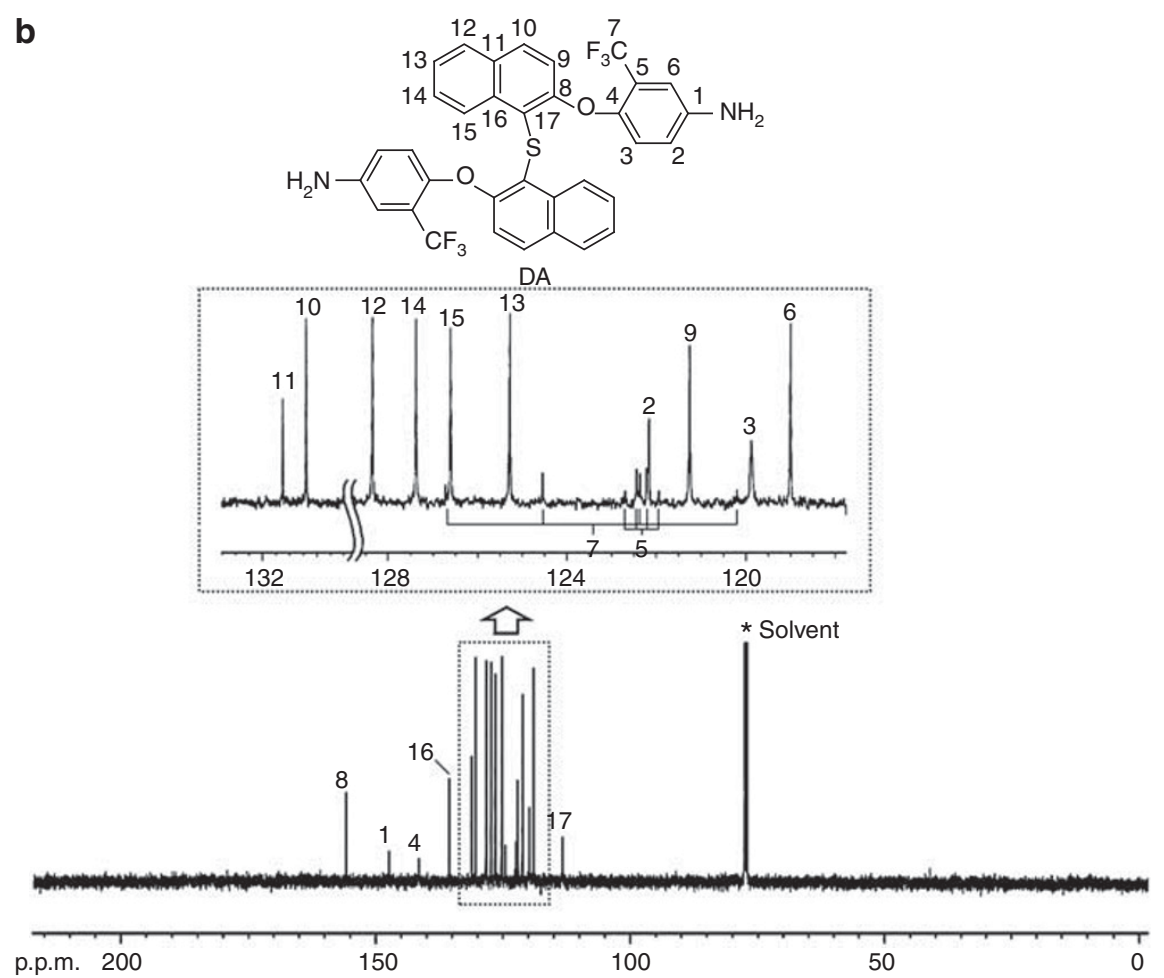

Figure $2{ }^{13} \mathrm{C}$ NMR spectra of (a) dinitro compound 1,1'-thiobis[2-(4-nitro-2-trifluoromethylphenoxy)naphthalene] and (b) diamine monomer 1,1'-thiobis[2-(4amino-2-trifluoromethylphenoxy)naphthalene.

groups have been completely converted into amino groups by the upfield shift of the aromatic protons and by the signal at 3.66 p.p.m. peculiar to the amino protons. As described in the experimental section, the ${ }^{13} \mathrm{C}$ NMR spectra of both dinitro DN and diamine DA compounds exhibited similar coupling patterns. There are two quartet peaks in the region of 118-126 p.p.m. due to the heteronuclear ${ }^{13} \mathrm{C}-{ }^{19} \mathrm{~F}$ coupling. The large quartet is due to the $\mathrm{CF}_{3}$ carbon with one-bond C-F coupling constant about $272 \mathrm{~Hz}$. The $\mathrm{CF}_{3}$-attached carbon also shows a clear quartet, with a smaller coupling constant of about $32 \mathrm{~Hz}$ due to two-bond $\mathrm{C}-\mathrm{F}$ coupling. These quartet signals corroborate the presence of $\mathrm{CF}_{3}$ group in the synthesized compounds. In the ${ }^{13} \mathrm{C}$ NMR spectrum of diamine DA (Figure 2), upfield shifts of the aromatic carbons, especially for those para $\left(\mathrm{C}^{4}\right)$ and ortho $\left(\mathrm{C}^{2}, \mathrm{C}^{6}\right)$ to the amino group, were also observed because of the resonance effect arising from the electron-donating nature of the amino group. The ${ }^{19} \mathrm{~F}$ NMR spectra of both DN and DA further confirmed the structure of 


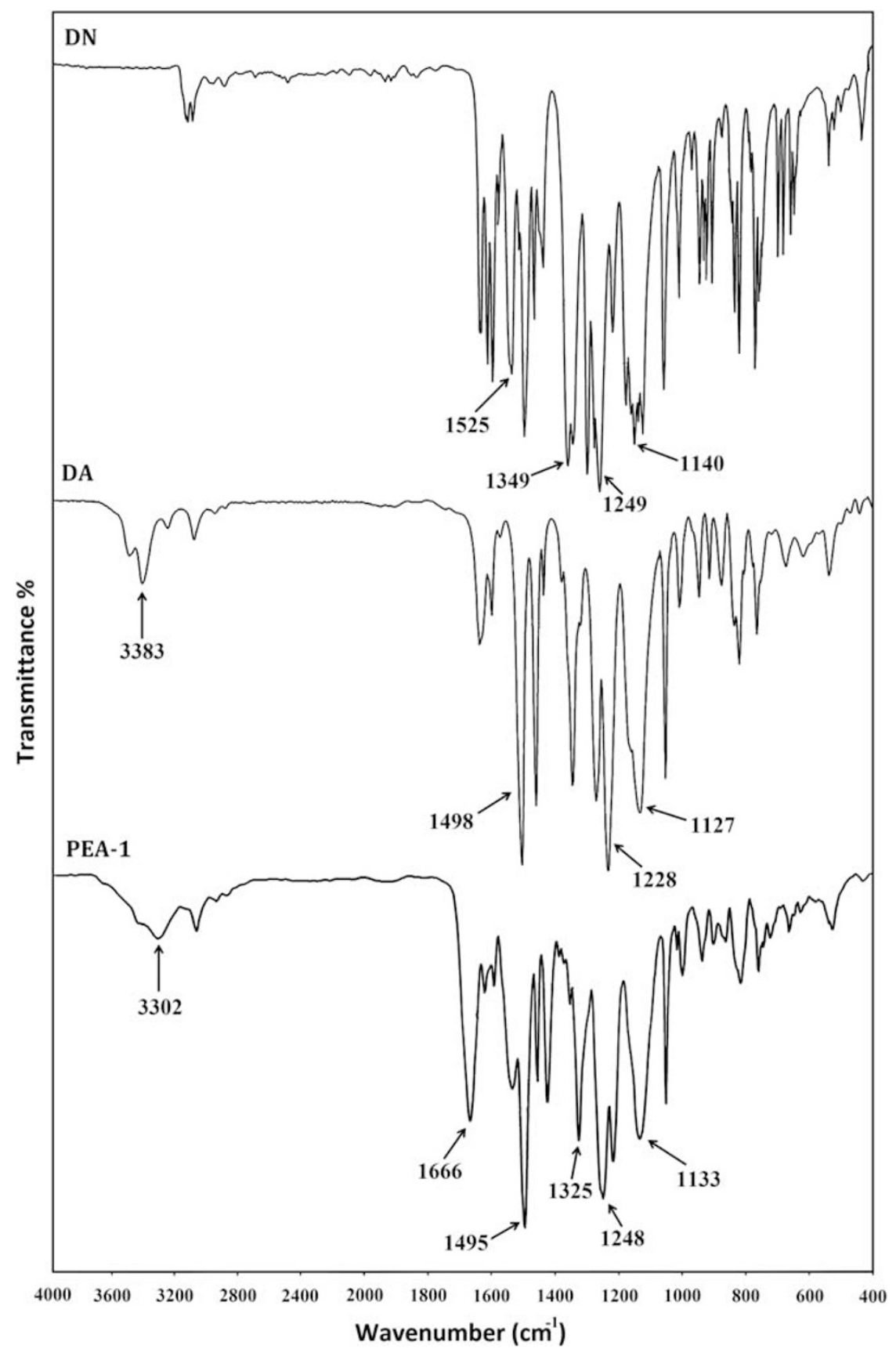

Figure 3 Infrared spectra of dinitro compound 1,1'-thiobis[2-(4-nitro-2-trifluoromethylphenoxy)naphthalene], diamine monomer 1,1'-thiobis[2-(4-amino-2trifluoromethylphenoxy)naphthalene and poly(ether amide)-1.

the resulting compounds. In ${ }^{19} \mathrm{~F}$ NMR spectra, fluorines in trifluoromethyl moieties appeared at -61.77 (s) and -62.19 (s) p.p.m. for DN and DA, respectively.

The FTIR spectra of DN and DA are shown in Figure 3. The nitro groups of compound DN gave two characteristic bands at 1525 and $1349 \mathrm{~cm}^{-1}\left(\mathrm{NO}_{2}\right.$ asymmetric and symmetric stretching). The characteristic absorptions of the nitro groups disappeared, and the characteristic bonds of amino groups at 3464 and $3383 \mathrm{~cm}^{-1}(\mathrm{~N}-\mathrm{H}$ stretching) and $1606 \mathrm{~cm}^{-1}(\mathrm{~N}-\mathrm{H}$ bending) appeared after reduction. Further characterization of DN and DA by elemental analysis provided experimental result, which was matched to the theoretical values, confirming the successful synthesis of the high-purity compounds.
Thus, all the spectroscopic data obtained are in good agreement with the expected structures of the dinitro compound DN and diamine monomer DA.

\section{Polymer synthesis}

The direct polycondensation of aromatic dicarboxylic acids with aromatic diamines using triphenyl phosphite and pyridine as condensing agents has been known to be an efficient method for the preparation of aromatic polyamides on laboratory scale. ${ }^{40}$ This method was successfully adopted here to prepare aromatic PEA-1PEA-8 from bis(ether amine) DA with various aromatic dicarboxylic acids 1-8, as shown in Scheme 2. Synthesis conditions and inherent 
<smiles>Nc1ccc(Oc2ccc3ccccc3c2Sc2c(Oc3ccc(N)cc3C(F)(F)F)ccc3ccccc23)c(C(F)(F)F)c1</smiles>

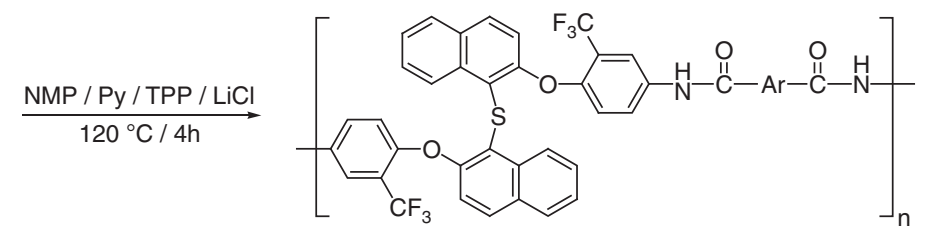

PEAs 1-8

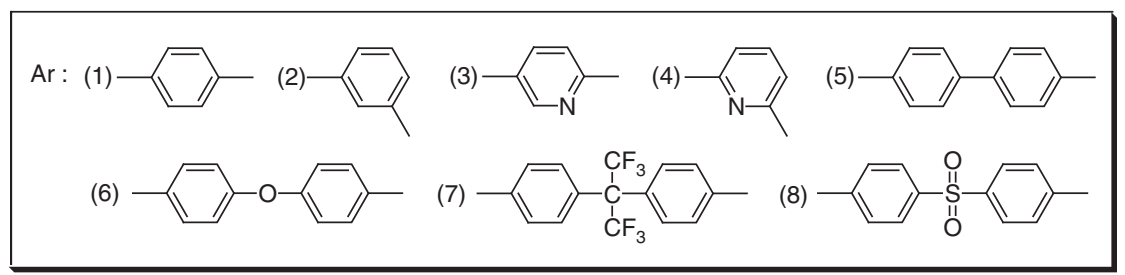

Scheme 2 Synthesis of the poly(ether amide)s.

Table 1 Synthesis conditions and inherent viscosities of PEAs

\begin{tabular}{llllc}
\hline & \multicolumn{4}{c}{ Amount of reagent used } \\
\cline { 2 - 4 } Polymer code & NMP $(\mathrm{ml})$ & Pyridine $(\mathrm{ml})$ & LiCl $(g)^{\mathrm{a}}$ & $\eta_{\text {inh }}{ }^{\mathrm{b}}\left(\mathrm{dlg}^{-1}\right)$ \\
\hline PEA-1 & $3+1^{\mathrm{c}}$ & 0.6 & 0.30 & 0.91 \\
PEA-2 & 3 & 0.5 & 0.30 & 0.66 \\
PEA-3 & 3 & 0.5 & 0.30 & 0.72 \\
PEA-4 & 2.5 & 0.5 & 0.25 & 0.61 \\
PEA-5 & $3+1$ & 0.6 & 0.30 & 0.93 \\
PEA-6 & 2.5 & 0.6 & 0.25 & 0.70 \\
PEA-7 & 2 & 0.4 & 0.20 & 0.77 \\
PEA-8 & 2.5 & 0.5 & 0.20 & 0.85 \\
\hline
\end{tabular}

Abbreviations: DA, 1,1'-thiobis[2-(4-amino-2-trifluoromethylphenoxy)naphthalene]; DMAc, $N, N$-dimethylacetamide; NMP, $N$-methyl-2-pyrrolidone; PEA, poly(ether amide); TPP, triphenyl phosphite.

${ }^{\mathrm{a}}$ Amount of each DA and diacid monomer $=1.0 \mathrm{mmol}$; TPP $=0.6 \mathrm{ml}$; reaction

temperature $=120^{\circ} \mathrm{C}$; and reaction time $=4 \mathrm{~h}$.

beasured at a concentration of $0.5 \mathrm{~g} \mathrm{dl}^{-1}$ in DMAc at $30^{\circ} \mathrm{C}$

' $3+1$ ' means that an initial amount of $3 \mathrm{ml} \mathrm{NMP}$ was used and an additional $1 \mathrm{ml}$ of NMP was added when the reaction solution became too viscous.

viscosities of the polymers are summarized in Table 1. All the polycondensations in NMP proceeded readily in a homogeneous solution. Tough and stringy precipitates formed when the viscous polymer solutions were trickled into the stirring methanol. These PEAs were obtained in high yields (92-97\%), and the inherent viscosities were in the range of $0.61-0.93 \mathrm{dl} \mathrm{g}^{-1}$, which were measured in DMAc solutions. The molecular weight of the polymers was high enough to obtain tough, flexible and transparent polymer films by casting from their DMAc solutions. The structural features of these PEAs were verified by elemental analysis and FTIR and ${ }^{1} \mathrm{H}$ NMR spectroscopies. The elemental analysis values generally agreed with the calculated values for the proposed structures of polymers (Table 2). However, because of the hygroscopic nature of the amide groups, the values of carbon were lower than the calculated values for the proposed structures. ${ }^{41}$ As expected, these fluorinated PEAs exhibited low moisture absorption values (1.09-2.17\%) due to the hydrophobic nature of the trifluoromethyl groups. The PEA-7 showed the lowest value on account of the higher fluorine content in the repeating unit. The low moisture absorptions also ensure that these polymers have stable dielectric performance. Figure 4 shows a typical ${ }^{1} \mathrm{H}$ NMR spectrum for PEA-1, in which all the protons are in good agreement with the proposed structure. The resonance peak appearing in the most downfield region, about 10.5 p.p.m., also supports the formation of amide linkages. The FTIR spectra of these PEAs exhibited the characteristic absorptions of polyamides at $3300-3400 \mathrm{~cm}^{-1}$ (N-H stretching), $1495-1550 \mathrm{~cm}^{-1}$ (combined $\mathrm{N}-\mathrm{H}$ bending and $\mathrm{C}-\mathrm{N}$ stretching) and $1650-1670 \mathrm{~cm}^{-1}(\mathrm{C}=\mathrm{O}$ stretching), with strong absorptions of aryl ether group and $\mathrm{C}-\mathrm{F}$ stretching in the region of $1100-1300 \mathrm{~cm}^{-1}$. The results further demonstrated that the fluorinated PEAs have the expected chemical structures.

\section{Polymer solubility}

Solubility of the polymer is a major factor that shows its processability for different applications. The solubility behavior of these fluorinated PEAs was determined by dissolving $0.05 \mathrm{~g}$ of polymers in $1 \mathrm{ml}$ of solvent, including NMP, DMSO, DMAc, N,N-dimethylformamide, pyridine, tetrahydrofuran, acetone and chloroform for $24 \mathrm{~h}$ at room temperature $\left(25^{\circ} \mathrm{C}\right)$ or upon heating in tightly closed vials, and showed that almost all the polymers were dissolved not only in highly polar solvents, such as NMP, DMSO, DMAc, and N,N-dimethylformamide, but also in moderate polar solvents, such as pyridine, tetrahydrofuran, acetone and chloroform. As indicated in Table 3, PEA-7 derived from 4,4'-(hexafluoroisopropylidene)dibenzoic acid showed an improved solubility compared with other polymers, especially in some low-boiling-point solvents. It should be noted that the good solubility in common low-boiling-point solvents is useful to prepare polyamide films or coatings at relatively low processing temperature, which is desirable for advanced microelectronics-manufacturing applications. The solubility of the PEAs derived from flexible diacids, such as PEA-4 and PEA-6, revealed a higher solubility due to the increased chain-packing distance and decreased intermolecular interactions. In addition, the unique enhanced 
Table 2 Elemental analysis and moisture uptake of PEAs

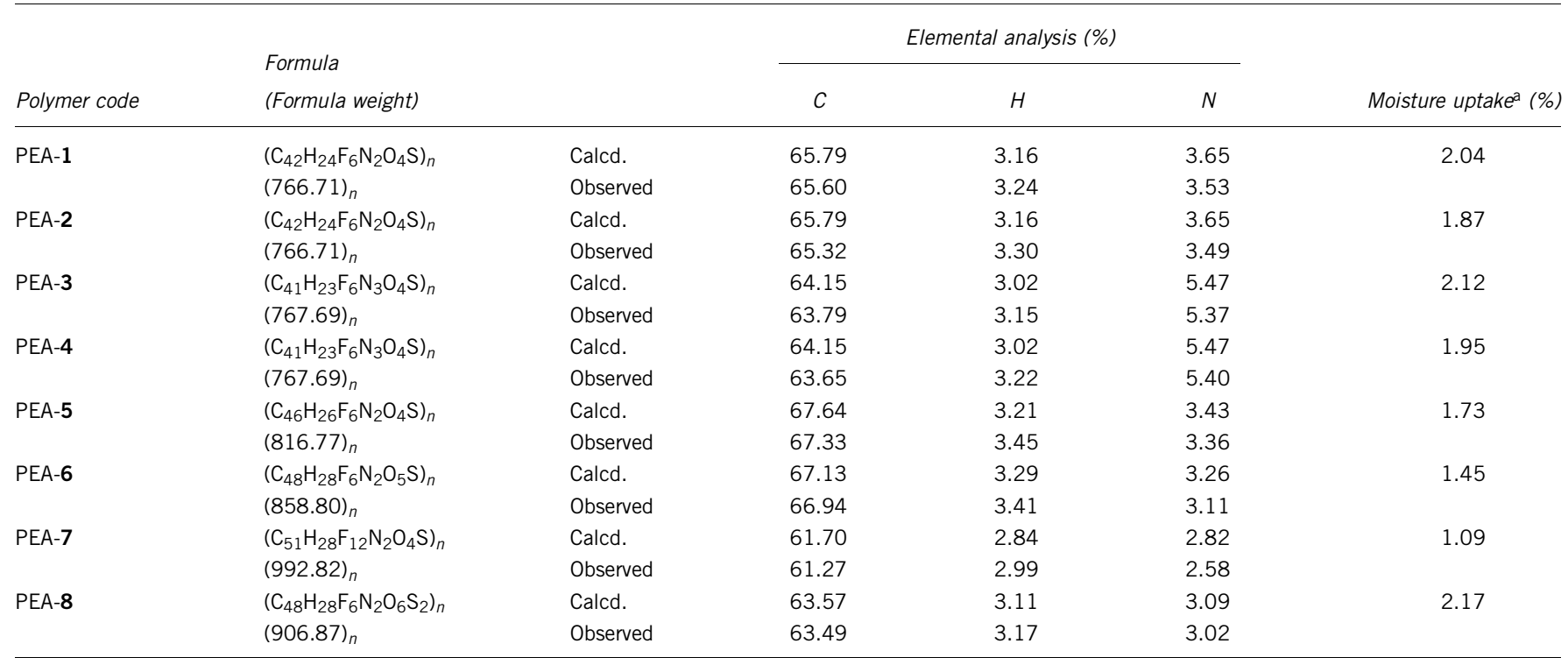

Abbreviations: calcd., calculated; PEA, poly(ether amide).

a Moisture uptake $(\%)=\left(W-W_{0} / W_{0}\right) \times 100 \%$, where $W$ is the weight of polymer sample after standing at room temperature and $W_{0}$ is the weight of polymer sample after being dried in vacuum at $100{ }^{\circ} \mathrm{C}$ for $12 \mathrm{~h}$.

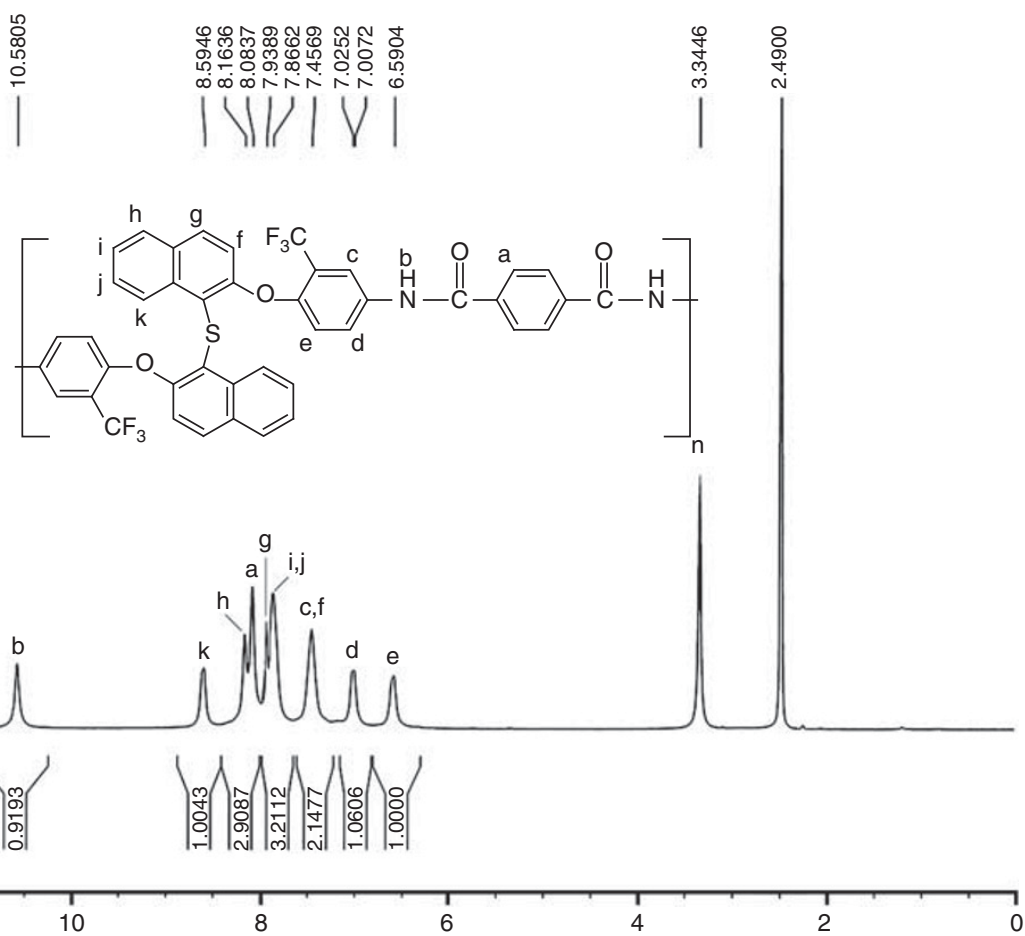

Figure $4{ }^{1} \mathrm{H}$ NMR spectrum of the fluorinated poly(ether amide)-1 (dimethyl sulfoxide- $d_{6}$ ).

solubility of the meta-related polymers (PEA-2 and PEA-4) might be attributed to the higher entropy state of the polymer chains, resulting from the meta linkages. In general, the excellent solubility of these PEAs can be attributed to the effect of the bulky $-\mathrm{CF}_{3}$ and naphthyl groups and the ortho-linked structure, which could inhibit close packing and reduced the interchain interactions to enhance solubility. The presence of flexible linkages (ether and thioether linkages) in the bis(ether amine) moiety also contributed to the enhancement in solubility. Owing to this flexibility, the packing of polymer chains in tight structures through hydrogen bonding between amide groups is probably disturbed and, consequently, the solvent molecules can penetrate easily to solubilize the chains. Because of the good solubility, flexible and strong cast films were easily obtained from DMAc solutions.

\section{X-ray diffraction of the polymers}

The morphological structure of the fluorinated PEAs was estimated by wide-angle $\mathrm{X}$-ray diffraction in a spectral window ranging from 
Table 3 Solubility ${ }^{a}$ of PEAs

\begin{tabular}{lcccccccc}
\hline & \multicolumn{7}{c}{ Solvent } \\
\cline { 2 - 8 } Polymer code & NMP & DMSO & DMAC & DMF & Pyridine & THF & Acetone & Chloroform \\
\hline PEA-1 & ++ & ++ & + & + & \pm & \pm & \pm & S \\
PEA-2 & ++ & ++ & ++ & ++ & + & + & \pm & \pm \\
PEA-3 & ++ & ++ & ++ & ++ & \pm & \pm & \pm & \pm \\
PEA-4 & ++ & ++ & ++ & ++ & + & + & + & \pm \\
PEA-5 & ++ & + & + & + & \pm & \pm & $S$ & - \\
PEA-6 & ++ & ++ & ++ & ++ & + & + & + & + \\
PEA-7 & ++ & ++ & ++ & ++ & ++ & ++ & + & + \\
PEA-8 & ++ & ++ & ++ & ++ & + & \pm & \pm & \pm \\
\hline
\end{tabular}

Abbreviations: DMAc, $\mathrm{N}, \mathrm{N}$-dimethylacetamide; DMF, $\mathrm{N}, \mathrm{N}$-dimethylformamide; DMSO, dimethyl sulfoxide; NMP, $\mathrm{N}$-methyl-2-pyrrolidone; PEA, poly(ether amide); S, swelling; THF, tetrahydrofuran.

asolubility measured at a polymer concentration of $0.05 \mathrm{~g} \mathrm{ml}^{-1}$

$(++)$, Soluble at room temperature; $(+)$, soluble after heating; $( \pm)$, partially soluble; and $(-)$ insoluble.

Table 4 Thermal characterizations of PEAs

\begin{tabular}{|c|c|c|c|c|}
\hline \multirow{3}{*}{$\begin{array}{l}\text { Polymer } \\
\text { code }\end{array}$} & \multirow{3}{*}{$\begin{array}{c}D S C \\
\mathrm{~T}_{g}^{b}\left({ }^{\circ} C\right)\end{array}$} & \multicolumn{3}{|c|}{$T G A$} \\
\hline & & \multicolumn{2}{|c|}{ Decomposition temperature $\left.{ }^{\mathrm{C}} \mathrm{C}\right)$} & \multirow{2}{*}{$\begin{array}{c}\text { Char } \\
\text { yield }(\%)\end{array}$} \\
\hline & & In air & In nitrogen & \\
\hline PEA-1 & 243 & 512 & 522 & 66 \\
\hline PEA-2 & 219 & 476 & 490 & 53 \\
\hline PEA-3 & 238 & 492 & 511 & 57 \\
\hline PEA-4 & 213 & 451 & 473 & 50 \\
\hline PEA-5 & 251 & 517 & 527 & 69 \\
\hline PEA-6 & 209 & 488 & 503 & 55 \\
\hline PEA-7 & 225 & 482 & 494 & 64 \\
\hline PEA-8 & 231 & 490 & 496 & 62 \\
\hline
\end{tabular}

Abbreviations: PEA, poly(ether amide); TGA, thermogravimetric analysis.

Temperature of $10 \%$ weight loss determined in nitrogen and air atmospheres.

${ }^{\mathrm{b}} T_{\mathrm{g}}$ measured by DSC at a scanning rate of $10^{\circ} \mathrm{C} \mathrm{min}^{-1}$ in flowing nitrogen.

${ }^{\mathrm{C}}$ Residual weight (\%) at $700^{\circ} \mathrm{C}$ in nitrogen.

$2 \theta=4-80^{\circ}$. The curves of all the polymers were broad and without obvious peak features, which indicate that they are all amorphous. The X-ray crystallography of TBN confirms the non-coplanar and twisty structure. ${ }^{42}$ Consequently, the highly amorphous nature of these PEAs is mainly attributed to the presence of the ortho-catenated sulfide linkage between two naphthalene rings. In addition, the introduction of bulky pendent $\mathrm{CF}_{3}$ and naphthyl groups decreases the backbone symmetry and regularity, through weakening intermolecular forces, such as hydrogen bonding between the polymer chains, and a lowering chain-packing efficiency, which results in decreased crystallinity. Thus, the amorphous structure of these PEAs also reflected in their excellent solubility in common organic solvents and good film-forming ability.

\section{Thermal properties}

The thermal properties of the polymers, which were evaluated by DSC and thermogravimetric analysis methods, are listed in Table 4. The DSC analysis shows that in each sample there is no evidence of crystallization and melting processes. Therefore, the polymers are in a full amorphous state and do not show any tendency to crystallize, even

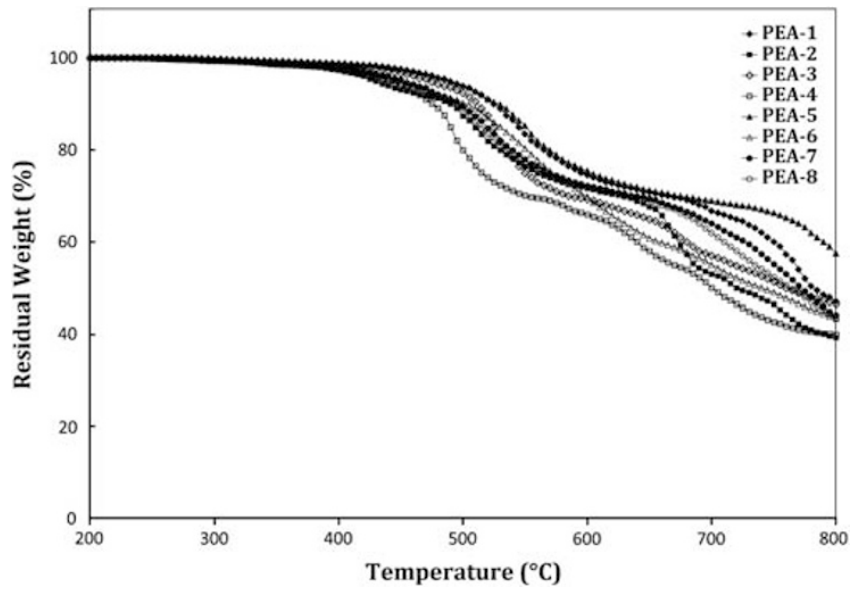

Figure 5 Thermogravimetric analysis curves of poly(ether amide)s with a heating rate of $10^{\circ} \mathrm{C} \mathrm{min}^{-1}$ in nitrogen atmosphere.

during the cooling step. The $T_{\mathrm{g}}$ values of aromatic PEAs were in the range of $209-251^{\circ} \mathrm{C}$, which follows the decreasing order of the chain flexibility and steric hindrance of the polymers backbones. In general, incorporation of less symmetric units leads to a decrease in $T_{\mathrm{g}}$. For example, polymers of diacids 2 and 4 , which contain meta-substituted phenylene rings units, have lower $T_{\mathrm{g}}$ values than do the analogous polymers of diacids 1 and 3, which contain para-substituted phenylene rings units, respectively. PEA-5 shows the highest $T_{\mathrm{g}}$ value of all the PEAs, which can be attributed to its rigid biphenylene segments in the polymer backbone. In addition, PEA-8 having the rigid sulfone groups in polymer backbones showed higher $T_{\mathrm{g}}$ value than corresponding PEA-6 and PEA-7.

The thermal and thermo-oxidative stabilities of the polymers were characterized by thermogravimetric analysis measurements in both nitrogen and air atmospheres. The temperatures at $10 \%$ weight loss $\left(T_{10}\right)$ were determined from the original thermograms and are tabulated in Table 4. These PEAs showed good thermal stability and had no notable weight loss below $500{ }^{\circ} \mathrm{C}$ in nitrogen atmosphere. $T_{10}$ values of the PEAs were in the range of $473-527^{\circ} \mathrm{C}$ in nitrogen and in the range of $451-517^{\circ} \mathrm{C}$ in air. The amount of residue of all PEAs at $700{ }^{\circ} \mathrm{C}$ in nitrogen atmosphere was higher than $50 \%$, especially PEA-5 had highest yield up to $69 \%$. The thermogravimetric curves of the PEAs in nitrogen atmosphere are shown in Figure 5. As expected, these polymers possessed excellent thermal stability, which could withstand the elevated processing. Thus, the introduction of flexible linkages (ether and thioether linkages) and pendant trifluoromethyl groups did not deteriorate their thermal stability significantly.

\section{Refractive index and dielectric constant of the polymers}

It is well known that the free volume and polarizability induced by various functional groups in a polymer can affect its refractive index. In general, a large free volume and small electronic polarizability decrease the refractive index. The fluorine atom exhibits a relatively low polarizability because of its high electronegativity and large steric volume, thus being able to lower the refractive index. ${ }^{43,44}$ As listed in Table 5, the in-plane $\left(n_{\mathrm{TE}}\right)$ and out-of-plane $\left(n_{\mathrm{TM}}\right)$ refractive indices of the PEA films range from 1.5633 to 1.5844 and from 1.5578 to 1.5754 , respectively. The average refractive indices $\left(n_{\mathrm{AV}}\right)$ estimated from the $n_{\mathrm{TE}}$ and $n_{\mathrm{TM}}$ values range between 1.5614 and 1.5813 in the order of PEA-8 $>$ PEA-3 $>$ PEA-4 $>$ PEA-5 $>$ PEA-1 $>$ PEA-2 $>$ PEA-6 $>$ PEA-7. As expected, all the resulting polymers had low refractive indices due 
Table 5 Refractive indices and dielectric constants of PEAs

\begin{tabular}{|c|c|c|c|c|c|}
\hline \multirow{2}{*}{$\begin{array}{l}\text { Polymer } \\
\text { code }\end{array}$} & \multicolumn{4}{|c|}{ Refractive indices and birefringence } & \multirow{2}{*}{$\begin{array}{l}\text { Dielectric } \\
\text { constants }^{\mathrm{e}}\end{array}$} \\
\hline & $\mathrm{n}_{T E}{ }^{\mathrm{a}}$ & $\mathrm{n}_{T M}{ }^{\mathrm{b}}$ & $\mathrm{n}_{A V^{\mathrm{C}}}$ & $\Delta \mathrm{n}^{\mathrm{d}}$ & \\
\hline PEA-1 & 1.5764 & 1.5679 & 1.5735 & 0.0085 & 2.72 \\
\hline PEA-2 & 1.5739 & 1.5666 & 1.5714 & 0.0073 & 2.72 \\
\hline PEA-3 & 1.5835 & 1.5754 & 1.5808 & 0.0081 & 2.75 \\
\hline PEA-4 & 1.5809 & 1.5740 & 1.5786 & 0.0069 & 2.74 \\
\hline PEA-5 & 1.5792 & 1.5695 & 1.5759 & 0.0097 & 2.73 \\
\hline PEA-6 & 1.5696 & 1.5632 & 1.5674 & 0.0064 & 2.70 \\
\hline PEA-7 & 1.5633 & 1.5578 & 1.5614 & 0.0055 & 2.68 \\
\hline PEA-8 & 1.5844 & 1.5753 & 1.5813 & 0.0091 & 2.75 \\
\hline
\end{tabular}

Abbreviations: AV, average; PEA, poly(ether amide)

${ }^{a} n_{\mathrm{TE}}$ : The in-plan refractive index at $1320 \mathrm{~nm}$ at ambient temperatures.

作

${ }^{c}$ Average refractive index; $n_{\mathrm{AV}}=\left(2 n_{\mathrm{TE}}+n_{\mathrm{TM}}\right) / 3$.

${ }^{c}$ Average refractive index; $n_{\mathrm{AV}}$
${ }^{\mathrm{d}}$ Birefringence; $\Delta n=n_{\mathrm{TE}}-n_{\mathrm{TM}}$.

dBirefringence; $\Delta n=n_{\mathrm{TE}}-n_{\mathrm{TM}}$.
eOptically estimated dielectric constant; $\varepsilon=1.10 n_{\mathrm{AV}}{ }^{2}$.

to the presence of $-\mathrm{CF}_{3}$ groups in the polymer backbone. Among them, PEA-7 shows the lowest refractive index (1.5614), which can be attributed to bulky hexafluoroisopropylidene $\left(-\mathrm{C}\left(\mathrm{CF}_{3}\right)_{2}-\right)$ groups in the polymer structure.

Birefringence expresses the level of optical anisotropy in the film, and it is defined as the difference in refractive index between two orthogonal planes of polarization. ${ }^{19}$ Moreover, the birefringence of polymer materials comes mainly from the preferred orientation of rigid groups and polymer chains. ${ }^{45}$ In this work, all the PEA films exhibited positive birefringence $(\Delta n=0.0055-0.0097)$, indicating that the molecular chains were preferentially aligned in the film plane. PEA-1 and PEA-3 having the para-linkages in polymer backbones showed higher birefringence than corresponding PEA-2 and PEA-4. The low birefringence of the PEAs can be mainly attributed to the naphthyl groups that are oriented perpendicularly to the polymer main chain. These bulky groups prevent the polymer chains from close packing and hence effectively hinder the in-plane orientation of the PEA main chains. In addition, both flexible ether and thioether linkages in the molecular chains of the PEAs contribute to lowering of the film birefringence by increasing the chain mobility and decreasing the chain packing.

Low dielectric constant polymers are widely studied as materials suitable for diverse technological applications in the electronics industry, such as stress buffers, flexible circuitry substrates, interlayer dielectrics and passivation layers. ${ }^{46}$ One of the most widely used strategies to decrease the dielectric constant is to introduce fluorine atoms into polymer materials. The $\varepsilon$-values estimated from average refractive indices of the resulting polymer films were in the range of 2.68-2.75 (Table 5). The low dielectric constants of the fluorinated PEAs could mainly be attributed to the presence of the bulky $-\mathrm{CF}_{3}$ groups in the diamine moiety, which resulted in less-dense chain packing and increased free volume. Moreover, the strong electronegativity of fluorine atoms results in very low polarizability of C-F bonds, thereby decreasing the dielectric constants. Hence, PEA-7 exhibited the lowest dielectric constants due to the presence of $-\mathrm{C}\left(\mathrm{CF}_{3}\right)_{2}-$ groups.

\section{CONCLUSION}

A novel trifluoromethyl containing diamine monomer, namely 1,1'-thiobis[2-(4-amino-2-trifluoromethylphenoxy)naphthalene], was designed, synthesized and used to polycondense with various aromatic diacids to form a series of fluorinated PEAs with flexible ether and thioether linkages, and bulky naphthyl groups in the main chain. These new aramids exhibited excellent solubility in various organic solvents, high thermal and thermo-oxidative stability, as well as low refractive indices, dielectric constants and moisture absorptions. According to the X-ray diffractograms and solubility data, the bulky trifluoromethyl and naphthyl groups, the flexible ether and thioether linkages, and ortho-catenated aromatic rings, which prevent polymer chains from packing well, are responsible for the amorphous and good solubility characteristics of all polymers.

\section{ACKNOWLEDGEMENTS}

We thank Professor Joel Mague (Tulane University, USA) for helpful discussions and Dr Salman Taheri for technical assistance with the NMR analysis.

1 Fink, J. K. High Performance Polymers (William Andrew Inc, New York, 2008).

2 Garcia, J. M., Garcia, F. C., Serna, F. \& de la Peña, J. L. High-performance aromatic polyamides. Prog. Polym. Sci. 35, 623-686 (2010)

3 Yang, H. H. Kevlar Aramid Fibers (Wiley, New York, 1992).

4 Yang, H. H. Aromatic High-Strength Fibers (Wiley, New York, 1989).

5 Sheng, S. R., Pei, X. L., Huang, Z. Z., Liu, X. L. \& Song, C. S. Novel soluble fluorinated aromatic polyamides derived from 2-(4-trifluoromethylphenoxy)terephthaloyl chloride with various aromatic diamines. Eur. Polym. J. 45, 230-236 (2009).

6 Mehdipour-Ataei, S., Sarrafi, Y., Hatami, M. \& Akbarian-Feizi, L. Poly(sulfone ether amide amide)s as a new generation of soluble, thermally stable polymers. Eur. Polym. J. 41, 491-499 (2005).

7 Liaw, D. J. \& Liaw, B. Y. Synthesis and characterization of new polyamide-imides containing pendent adamantyl groups. Polymer 42, 839-845 (2001).

8 Yang, C. P., Chen, Y. P. \& Woo, E. M. Fluorinated polyamides and poly(amide imide)s based on 1,4-bis(4-amino-2-trifluromethylphenoxy)benzene, aromatic dicarboxylic acids, and various monotrimellitimides and bistrimellitimides: syntheses and properties. J. Polym. Sci., Part A: Polym. Chem. 42, 3116-3129 (2004).

9 Anton, D. Surface-fluorinated coatings. Adv. Mater. 10, 1197-1205 (1998).

$10 \mathrm{Ma}$, H., Jen, A. Y. \& Dalton, L. R. Polymer-based optical waveguides: materials, processing, and devices. Adv. Mater. 14, 1339-1365 (2002).

11 Zhou, M. Low-loss polymeric materials for passive waveguide components in fiber optical telecommunication. Opt. Eng. 41, 1631-1643 (2002).

12 Li, G., Wang, J., Guixian, S., Jian, X., Wang, L. \& Zhao, M. Synthesis and characterization of fluorinated crosslinkable poly(phthalazinone ether)s bearing tetrafluorostyrene groups for optical waveguides. Polym. J. 42, 880-886 (2010).

13 Banerjee, S., Maier, G., Dannenberg, C. \& Spinger, J. Gas permeabilities of novel poly(arylene ether)s with terphenyl unit in the main chain. J. Membr. Sci. 229, 63-71 (2004).

14 Niwa, M., Kawakami, H., Kanamori, T., Shinbo, T., Kaito, A. \& Nagaoka, S. Gas separation of asymmetric 6FDA polyimide membrane with oriented surface skin layer. Macromolecules 34, 9039-9044 (2001).

15 Maji, S. \& Banerjee, S. Synthesis, characterization, and properties of novel uorine containing aromatic polyamides. J. Appl. Polym. Sci. 108, 1356-1364 (2008).

16 Li, P. H., Wang, C. Y., Li, G. \& Jiang, J. M. Synthesis and characterization of novel polyamides derived from 1,4-bis((4-amino-2-(trifluoromethyl)phenoxy)methyl)cyclohexane and aromatic dicarboxylic acids. Polym. Bull. 64, 127-140 (2010).

17 Yang, C. P., Su, Y. Y. \& Hsu, M. Y. Syntheses and properties of fluorinated polyamides and poly(amide imide)s based on 9,9-bis[4-(4-amino-2-trifluromethylphenoxy)phenyl]fluroene, aromatic dicarboxylic acids, and various monotrimellitimides and bistrimellitimides. Colloid. Polym. Sci. 284, 990-1000 (2006).

18 Liaw, D. J., Huang, C. C., Hu, C. K., Lee, K. R. \& Lai, J. Y. High optical transparency, low dielectric constant and light color of novel organosoluble polyamides with bulky alicyclic pendent group. Polymer 48, 6571-6580 (2007).

19 Liaw, D. J., Huang, C. C. \& Chen, W. H. Color lightness and highly organosoluble fluorinated polyamides, polyimides and poly(amide-imide)s based on noncoplanar 2,2'-dimethyl-4,4'-biphenylene units. Polymer 47, 2337-2348 (2006).

20 Sheng, S. R., Pei, X. L., Huang, Z. Z., Liu, X. L. \& Song, C. S. Novel soluble fluorinated aromatic polyamides derived from 2-(4-trifluoromethylphenoxy)terephthaloyl chloride with various aromatic diamines. Eur. Polym. J. 45, 230-236 (2009).

21 Hsiao, S. H., Yang, C. P. \& Huang, S. C. Preparation and properties of new polyimides and polyamides based on 1,4-bis(4-amino-2-trifluoromethylphenoxy)naphthalene. J. Polym. Sci., Part A: Polym. Chem. 42, 2377-2394 (2004).

22 Tan, J., Wang, C., Peng, W., Li, G. \& Jiang, J. M. Synthesis, characterization, and properties of novel aromatic polyamides containing phthalazinone moiety. Polym. Bull. 62, 195-207 (2009).

23 Liou, G. S., Fang, Y. K. \& Yen, H. J. Synthesis and properties of noncoplanar rigid-rod aromatic polyamides containing phenyl or naphthyl substituents. J. Polym. Res. 14, $147-155$ (2007). 
24 Ding, Y., Hlil, A. R. \& Hay, A. S. Syntheses of semicrystalline aromatic poly(thioether thioether ketone)s (PTTK and PTBTK) and their copolymers with ether analogues. Macromolecules 32, 315-321 (1999).

25 Berti, C., Celli, A., Marianucci, E. \& Vannini, M. Preparation and characterisation of novel random copoly(arylene ether-thioether ketone)s containing 2,2-bis(4-phenylene)propane units. Eur. Polym. J. 43, 2453-2461 (2007).

26 Suzuki, Y., Higashihara, T., Ando, A. \& Ueda, M. Synthesis of high refractive index poly(thioether sulfone)s with high abbe's number derived from 2,5-is(sulfanylmethyl)I,4-dithiane synthesis of poly(thioether sulfone)s. Polym. J. 41, 860-865 (2009).

27 Matsumura, S., Kihara, N. \& Takata, T. Properties of a few aromatic poly(thioether ketones) as sulfur-containing high performance polymers. J. Appl. Polym. Sci. 92, 1869-1874 (2004).

28 Yang, C. P. \& Cherng, J. J. Synthesis and properties of aromatic polyamides derived from 1,2-bis(4-aminophenoxy)benzene and aromatic dicarboxylic acids. J. Polym. Sci., Part A: Polym. Chem. 33, 2209-2220 (1995).

29 Hsiao, S. H., Yang, C. P., Tsai, C. Y. \& Liou, G. S. A novel class of organosoluble and light-colored fluorinated polyamides derived from 2,2-bis(4-amino-2-trifluoromethylphenoxy)biphenyl or 2,2-bis(4-amino-2-trifluoromethylphenoxy)-1,1-binaphthyl. Eur. Polym. J. 40, 1081-1094 (2004).

$30 \mathrm{Hsiao}, \mathrm{S}$. H. \& Chu, K. Y. Synthesis and properties of ortho-linked aromatic polyamides based on 4,4-(2,3-naphthalenedioxy) dibenzoic acid. J. Polym. Sci., Part A: Polym. Chem. 35, 3385-3391 (1997).

31 Hsiao, S. H. \& Chang, C. F. Synthesis and properties of aromatic polyamides based on 4,4-[1,4(1,3 or 1,2)-phenylenedioxy]dibenzoic acid. Macromol. Chem. Phys. 197, 1255-1272 (1996).

32 Shockravi, A., Mehdipour-Ataei, S., Abouzari-Lotf, E. \& Yousefi, A. Sulfide and sulfoxide based poly(ether-amide)s: synthesis and characterization. Eur. Polym. J. 42, 133-139 (2006).

33 Shockravi, A., Mehdipour-Ataei, S., Abouzari-Lotf, E. \& Zakeri, M. Soluble and thermally stable polyamides bearing $1,1^{\prime}$-thiobis(2-naphthoxy) groups. Eur. Polym. J. 43, 620-627 (2007).

34 Shockravi, A., Abouzari-Lotf, E., Javadi, A. \& Atabaki, F. Preparation and properties of new ortho-linked polyamide-imides bearing ether, sulfur and trifluoromethyl linkages. Eur. Polym. J. 45, 1599-1606 (2009).
35 Shockravi, A., Abouzari-Lotf, E., Javadi, A. \& Taheri, S. Synthesis and properties of novel fluorinated polyamides based on noncoplanar sulfoxide containing aromatic bis(ether amine). Polym. J. 41, 174-180 (2009).

36 Shockravi, A., Abouzari-Lotf, E. \& Javadi, A. Synthesis and properties of organosoluble fluorinated polyamides bearing $2-2$ - thio-bis(4-methyl phenoxy) groups. Des. Monomers Polym. 12, 119-128 (2009).

37 Abouzari-Lotf, E., Shockravi, A. \& Javadi, A. Heat-resistant and soluble fluorinated poly(amide-imide)s based on noncoplanar ortho-linked diimide-dicarboxylic. Polym. Degrad. Stab. 96, 1022-1028 (2011).

38 Gazdar, M. \& Smiles, S. Aromatic hydroxy-sulphoxides. J. Chem. Soc. 97, 2248-2253 (1910).

39 Bosese, D., Lee, H., Yoon, D. Y., Swalen, J. D. \& Rabolt, J. F. Chain orientation and anisotropies in optical and dielectric properties in thin films of stiff polyimides. J. Polym. Sci., Part B: Polym. Phys. 30, 1321-1327 (1992).

40 Yamazaki, N., Matsumoto, M. \& Higashi, F. Studies on reactions of the N-phosphonium salts of pyridines. XIV. Wholly aromatic polyamides by the direct polycondensation reaction by using phosphites in the presence of metal salts. J. Polym. Sci., Part A: Polym. Chem. 13, 1373-1380 (1975)

41 Liaw, D. J. \& Liaw, B. Y. Synthesis and characterization of new poly(amide-imide)s from 1,4-bis(4-trimellitimidophenoxy)-2-tert-butylbenzene with various diamines. J. Polym. Sci., Part A: Polym. Chem. 36, 2301-2307 (1998).

42 Mague, J. T., Balakrishna, M. S., Punji, B. \& Suresh, D. Two crystalline modifications of 1,1'-thiobis(2-naphthol). Acta Cryst. C. 63, 487-488 (2007).

43 Groh, W. \& Zimmermann, A. What is the lowest refractive index of an organic polymer? Macromolecules 24, 6660-6663 (1991).

44 Hougham, G., Tesoro, G. \& Viehbeck, A. Influence of free volume change on the relative permittivity and refractive index in fluoropolyimides. Macromolecules 29, 3453-3456 (1996).

45 Lee, K. S., Kim, J. P. \& Lee, J. S. Synthesis and characterization of low-birefringent crosslinkable fluorinated poly(arylene ether sulfide)s containing pendant phenyl moiety. Polymer 51, 632-638 (2010).

46 Yang, C. P., Chen, R. S. \& Chen, K. H. Light-colored and soluble fluorinated polyimides based on 2-trifluoromethyl-4,4'-diaminodiphenyl ether and various aromatic dianhydrides. Colloid. Polym. Sci. 281, 505-515 (2003). 